\title{
Intelligent connection of a hybrid generator (PV/Wind) to low-voltage electric grid
}

\author{
M. F. Almi ${ }^{\mathrm{a}, \mathrm{b}}$, M. Arrouf ${ }^{\mathrm{a}}$, H. Belmili ${ }^{\mathrm{b}, *}$ \\ ${ }^{a}$ Département électrotechnique, Université Batna2, Batna, 05000, Algéria \\ ${ }^{b}$ Unité de Développement des Equipements Solaires (UDES), EPST/CDER, Route Nationale $N^{\circ}: 11$, Bou-Ismail, BP 365 Tipaza, \\ 42004, Algérie
}

\begin{abstract}
This paper presents the study and optimization of micro grid-connected PV/Wind hybrid system in Algeria. The aim of the study is to achieve the best configuration and install the PV/Wind hybrid system with the best quality/price ratio (where it is needed and with the simplest possible configuration). The simplicity of the power system contributes to reducing its maintenance cost and increasing its reliability. For this aim, a new strategy based on the optimization of the energy extracted from these sources, by choosing the best combination (location/configuration). Will presented in this work using a low-voltage three-phase network to get rid of the storage problem, and with the ability to operate in islanding mode to supply consumers with electrical energy in case of electricity shortage resulting from a failure of this latter, and thus limited the number of consumers affected by this network breakdown. These systems could be implemented by, farmers, cooperatives, individuals, and local communities considered as electricity producers in this case. The simulation results show the control performance and dynamic behavior of the PV/Wind system and islanding mode.
\end{abstract}

Keywords: Photovoltaic, wind, smart grid, islanding monitoring

\section{Introduction}

To meet today's increasing energy needs, it is necessary to find non exhaustive and diversified solutions. Currently, there are basically two possible ways tackle this issue; the first way consists on reduce the customers electric energy consumption, the second way consists on devising and promote new energy sources and improve their efficiency [1]. Algeria is the Africa's largest natural gas producer and second largest oil producer, after Nigeria. Its production accounted for almost 70 percent of government budget revenue and grants and about 98 percent of export earnings in 2014, according to the international monetary fund [2]. In a country such Algeria, it is not conceivable to abandon hydrocarbons in the production of electricity. But, since Algeria has a great solar resource and an exploitable wind potential, the complementarity of these two sources can be used as hybrid generators (PV/Wind) connected to micro-grid in remote or arid areas where it is profitable (wind and sunny sites). Thus, we can increase the penetration of clean energy in electricity generation in a more profitable way.

\section{General Configuration of a System}

The proposed hybrid PV/Wind system, is shown in, Fig. 1, it is composed of a variable-speed wind turbine, coupled to a permanent magnet synchronous generator (PMSG) and PV array, without energy storage [3]. It can be considered as a small-scale alternative source of electrical energy where conventional generation is not practical. The two energy sources are connected to a common DC bus line.

\footnotetext{
* Manuscript received September 11, 2018; revised May 2, 2019.

Corresponding author. Tel.: +213775221717; E-mail address: fayalmi@ hotmail.fr.

doi: $10.12720 /$ sgce.8.4.453-460
} 
Through a DC/DC converter for the PV system, and AC/DC converter for the wind system. $\mathrm{V}_{\mathrm{DC}}$ is set to a fixed DC bus line voltage. Each source is controlled independently to extract their maximum power MP. An inverter is used to supply the AC loads, to connect to the grid, and islanding monitoring.

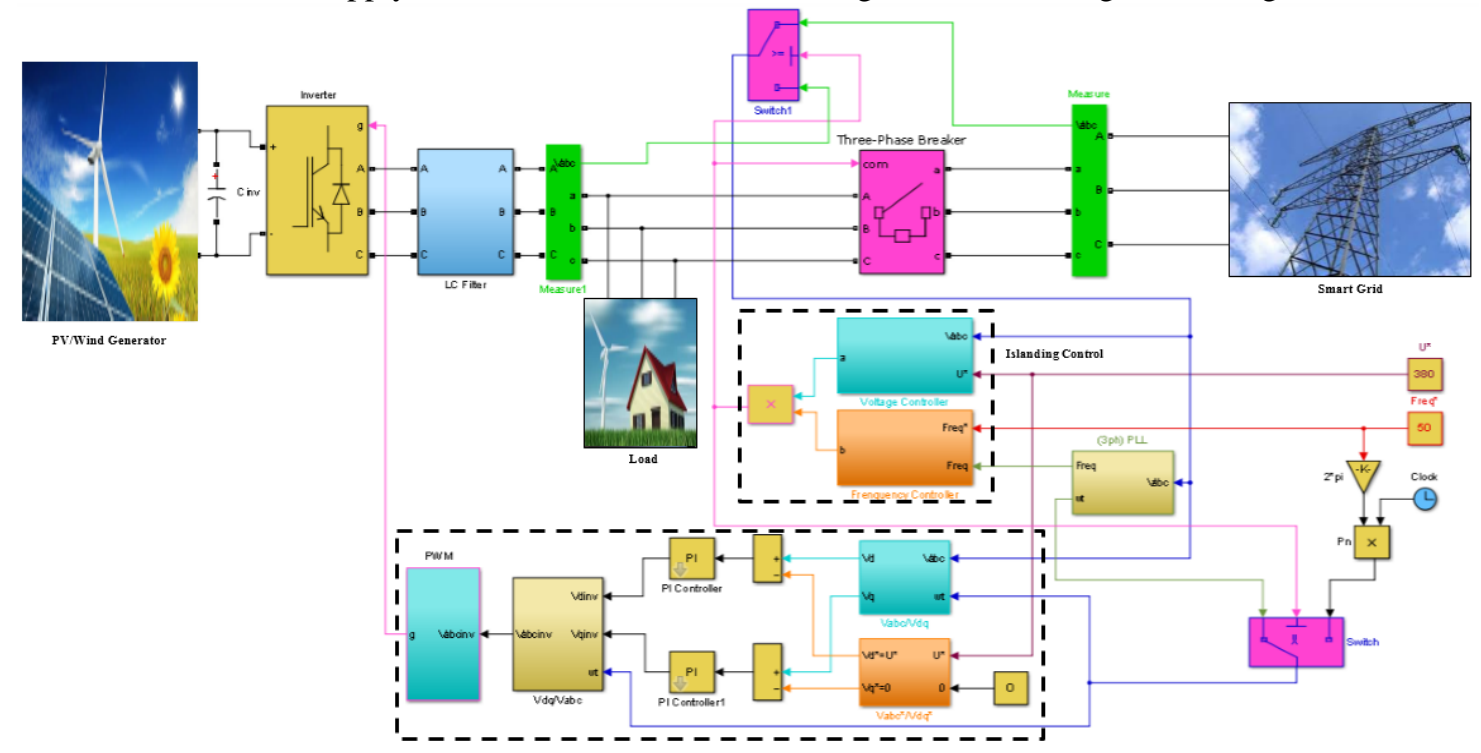

Fig. 1. Hybrid (PV/Wind) system illustration.

\section{Control Strategy}

The control strategy aims to ensure maximum power point tracking (MPPT) to make the wind and the PV generators work in their maximum power mode, this increases the energy captured from the wind and the solar radiation. In addition, the DC bus voltage should be adjusted at the inverter supplying the utility grid.

\subsection{Wind control}

One of the main goals of this part of the study is to simplify the structure of the energy conversion chain dedicated to small scale wind turbines. This is necessary in order to reduce the overall cost without significantly reducing the energy efficiency of the system. The configuration based on a six controlled interrupters bridge rectifier is expensive; it involves mechanical measurement devices and requires fairly complex control circuitry. Instead, we have used a diode rectifier and a boost converter, which has the advantages of a low and simple control task [4]-[5]. As shown in Fig. 2.

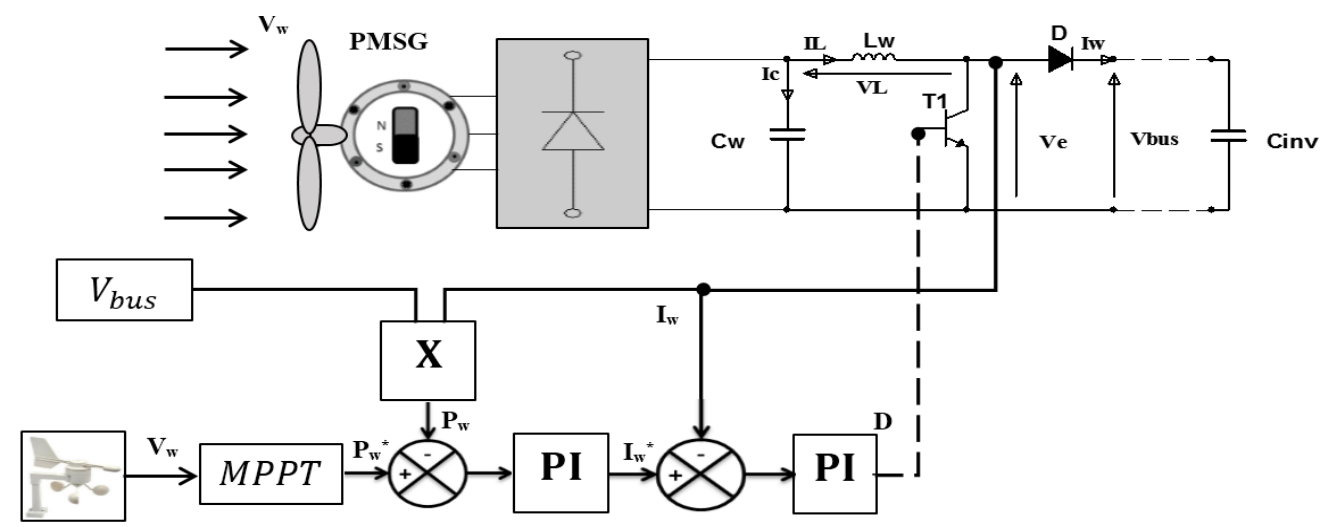

Fig. 2. Wind generator control. 


\subsection{PV control}

The proposed PV control system is depicted in Fig. 3, where the power extracted from the photovoltaic generator can be maximized by adjusting the boost converter output current and stabilizing the DC bus voltage to a reference value [7]. As shown in Fig. 4, Fig. 5, Fig. 6 and Fig. 7.

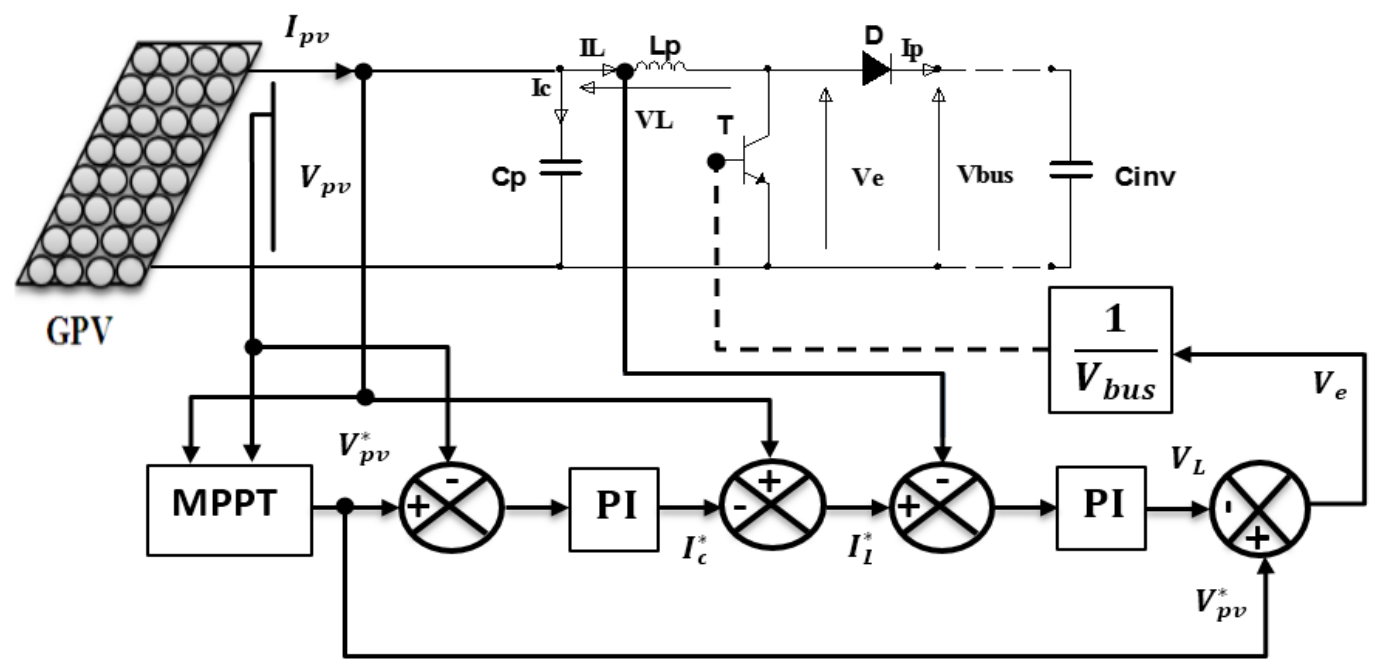

Fig. 3. Photovoltaic generator control.

\subsection{Maximum power point tracking for wind power generator}

A typical wind energy conversion system produces its maximum power at a maximum value of power coefficient $C_{p_{-} \text {opt }}$ [4], so it is necessary to keep the rotor speed at the optimum value of the tip speed ratio, $\lambda_{\text {opt }}(1,2)$, as shown in Fig. 8 and Fig. 9.

$$
\begin{aligned}
& P_{w_{-} o p t}=\frac{1}{2} \times \rho \times A \times C_{p_{-} o p t}\left(\frac{R \times \Omega_{o p t}}{\lambda_{o p t}}\right)^{3}=K_{o p t} \times \Omega_{o p t}^{3} \\
& \Omega_{o p t}=\frac{\lambda_{o p t}}{R} \times v=K_{w} \times v
\end{aligned}
$$

\subsection{Maximum power point tracking for $P V$ generator}

The most commonly used MPPT algorithm is the incremental conductance (INC), due to its ease of implementation in its basic form [6]. Where $\mathrm{dP} / \mathrm{dV}$ should be zero at MPP, and the sign of $\mathrm{dP} / \mathrm{dV}$ may be identified by (3).

$$
\frac{d I}{d V}=-\frac{I}{V}
$$

\section{Network Connection Control}

The network connection control strategy aims at setting the inverter to control independently the frequency and amplitude of the voltage supplied to a load. Closed control loops used by these controls ensure fast transient response and high state performance [8].

The proposed control scheme is presented in Fig. 1. 


\section{Islanding Detection and Load Shedding}

The most important parameters of electrical networks are the amplitude of the voltage and its frequency. An abnormal variation in these parameters can cause a serious problem or even damage to the network [9]-[10]. To avoid these damages and mitigate the problem, protective relays are installed in the different points of the grid-connection. The reaction time of its relays is very short and is around a few tenths of seconds. For this reason, internal or external monitoring devices to the inverter should be installed. For analyzing the parameters of the electrical signal and coupling or decoupling the hybrid generator (PV/Wind) to or from the electric network.

\section{Frequency Monitoring}

Frequency monitoring is achieved by a three-phase locked loop (PLL-dq-park), which allows having grid voltage and the frequency to supervise, these two parameters will be compared with two thresholds values corresponding to $f_{\text {threshld }}=(50 \pm 0.5) \mathrm{Hz}$.

$$
f_{\text {minthreshold }} \prec f_{\text {est }} \prec f_{\text {maxthreshold }}
$$

If the threshold is crossed during more than $0.1 \mathrm{~s}$. The (PV/Wind) hybrid generator and the load are disconnected from the grid (stand-alone system). If the grid frequency lays between these thresholds, the hybrid generator and the load are reconnected to the grid. As shown in Fig. 10, and Fig. 11.

\section{Voltage Monitoring}

The RMS voltage to be supervised will be compared with two threshold values corresponding to $U_{\text {threshld }}=(380 \pm 57) \mathrm{V}$.

$$
U_{\text {minthreshold }} \prec U_{\text {abcest }} \prec U_{\text {maxthreshold }}
$$

If a threshold is crossed during more than $0.1 \mathrm{~s}$ the (PV/Wind) hybrid generator and the load is disconnected from the grid (stand-alone system). If the grid voltage is between these thresholds values, the hybrid generator, and the load are reconnected to the grid. As shown in Fig. 12 and Fig. 13.

\section{Simulation Results}

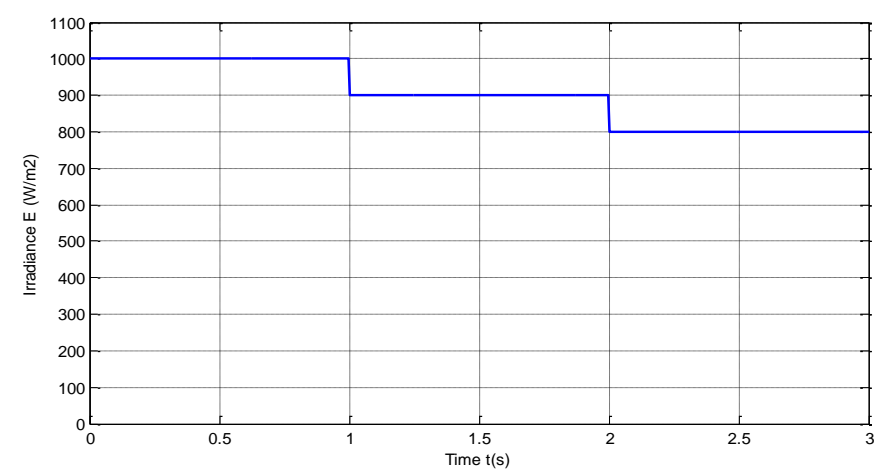

Fig. 4. Solar irradiance. 


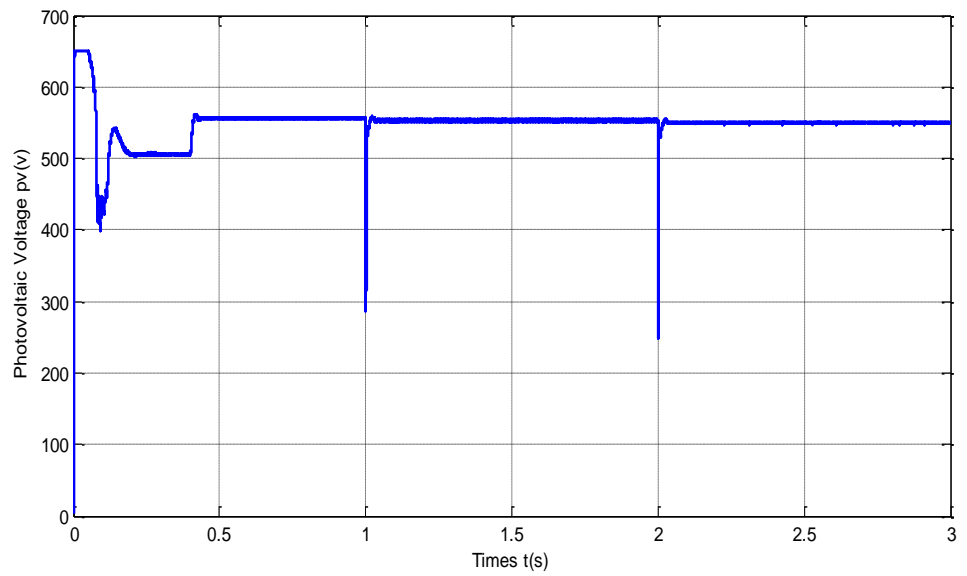

Fig. 5. Photovoltaic voltage.

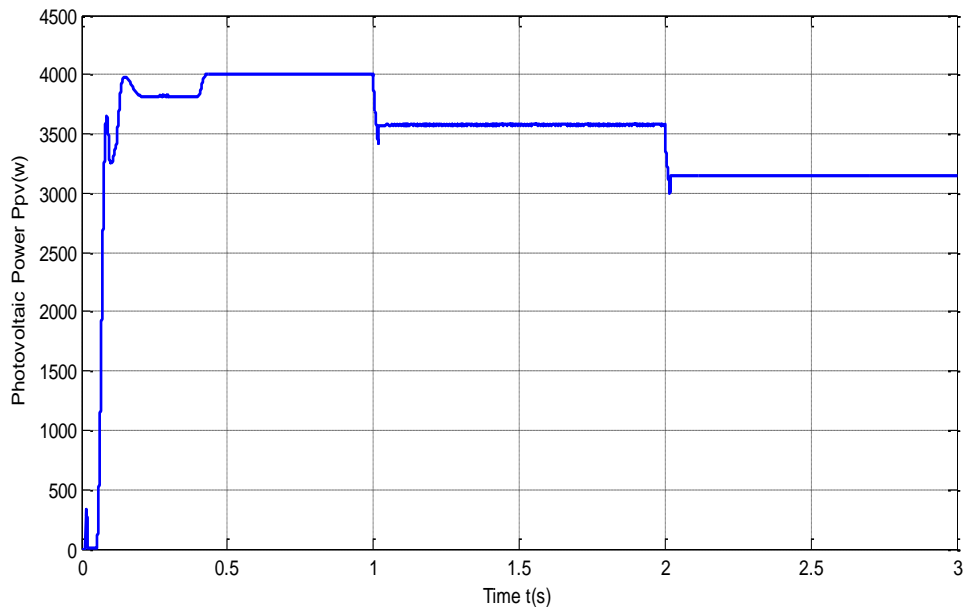

Fig. 6. Photovoltaic power.

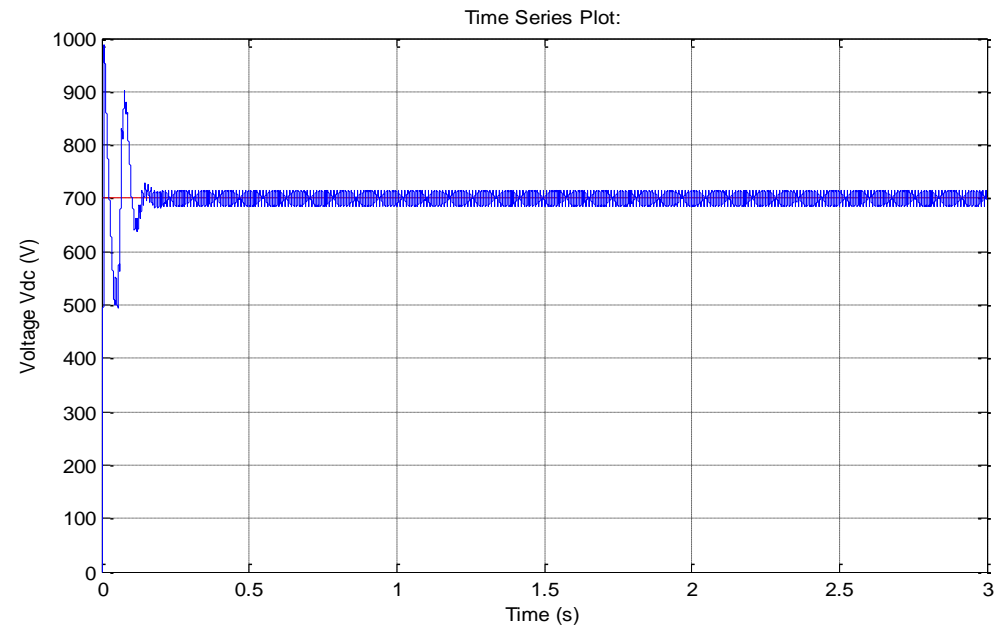

Fig. 7. DC bus voltage. 


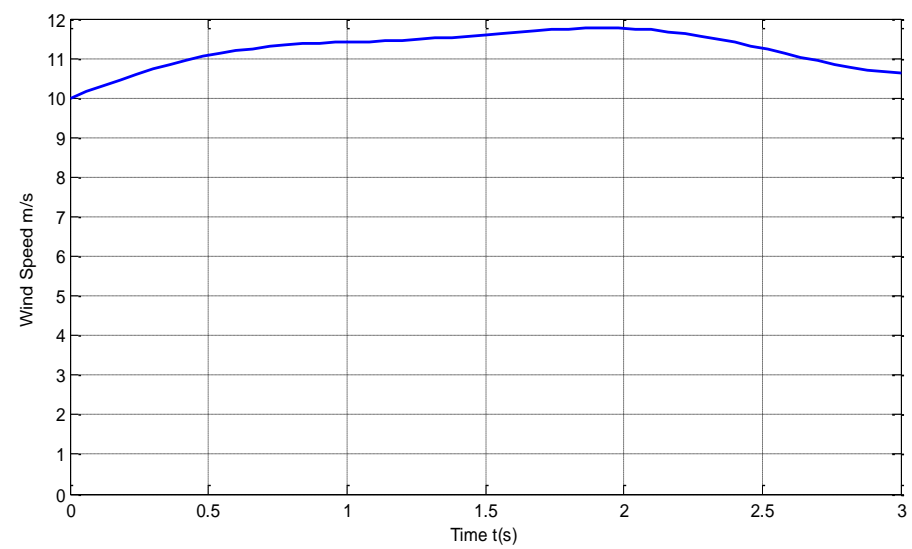

Fig. 8. Wind speed.

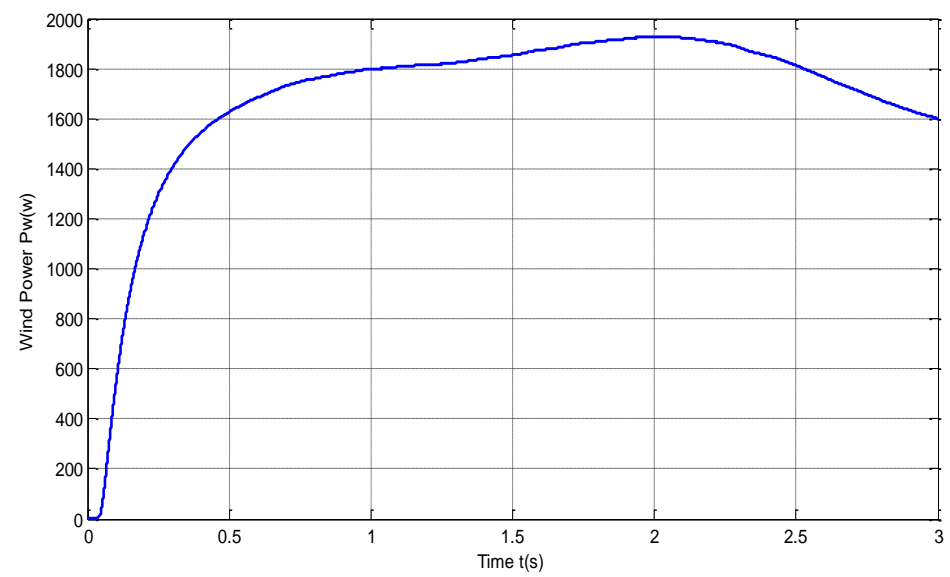

Fig. 9. Wind turbine power.

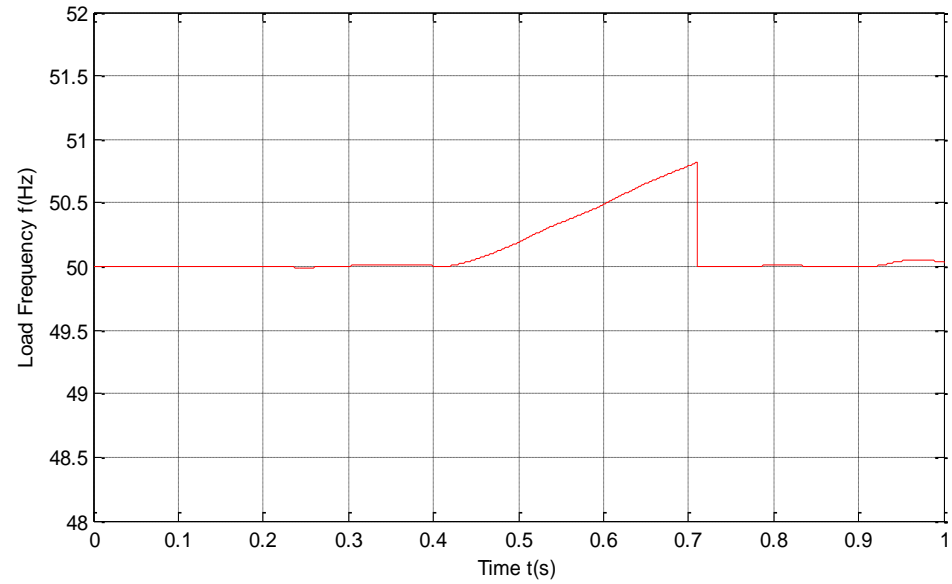

Fig. 10. Load frequency. 


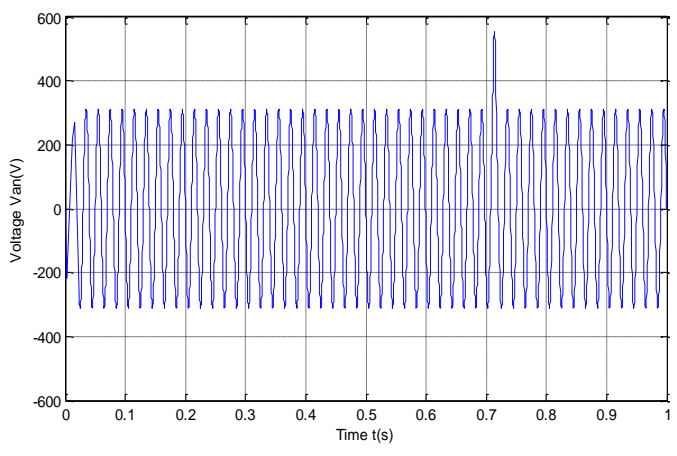

(a)

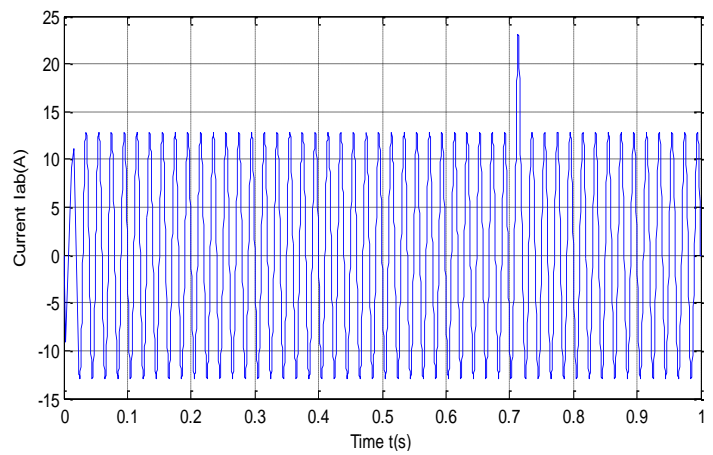

(b)

Fig. 11. Load (a. voltage and b. current).

The purpose of this simulation is to check the operation of the "frequency monitoring". The frequency of the grid undergoes a variation of the ramp type. This variation begins at $t=0.42 \mathrm{~s}$ from $50 \mathrm{~Hz}$ and reaches $50.5 \mathrm{~Hz}$, at $\mathrm{t}=0.61 \mathrm{~s}$ as shown in Fig. 10. Currents and voltages follow the variations that appear as minimal. After a second at $\mathrm{t}=0.71 \mathrm{~s}$, the system triggers the shutdown device that isolates the hybrid generator (PV/Wind) from the grid as shown in Fig. 11(a,b). Or the current and the voltages as well as the frequency return to their initial values, by taking the reference values $\mathrm{V}_{\mathrm{an}}=220 \mathrm{~V}$ and $\mathrm{f}=50 \mathrm{~Hz}$.

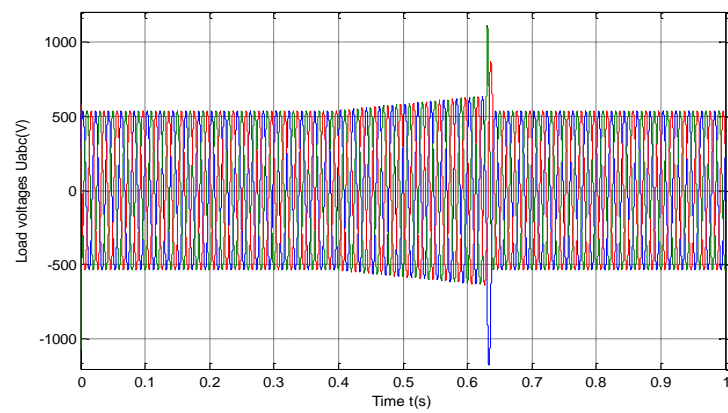

(a)

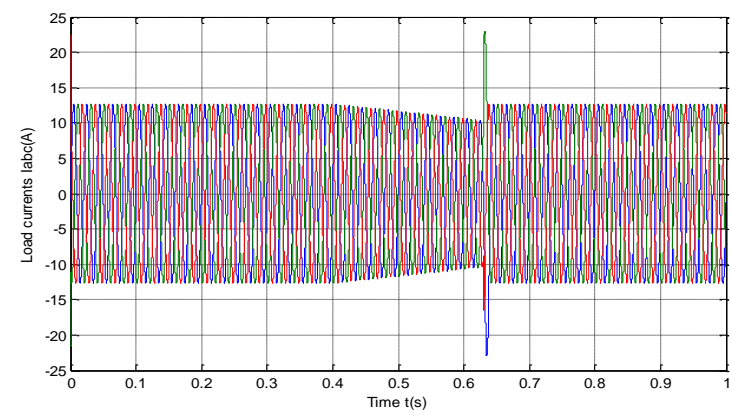

(b)

Fig. 12. Load (a. voltage and b. current) in over-load case.

The purpose of this simulation is to show that the decoupling system is able to detect the surge and isolates the hybrid generator (PV/Wind) from the grid. A gradual overvoltage starts at $t=0.4 \mathrm{~s}$. The maximum threshold voltage is reached around $0.53 \mathrm{~s}$ as shown in Fig. 12(a, b). As the grid voltage increases and the power to be transmitted on the network is constant, network currents $\mathrm{I}_{\mathrm{abc}}$ decrease. The system responds after $0.1 \mathrm{~s}$ from the instant when the maximum voltage threshold has been reached. The current and the voltages $\left(\mathrm{U}_{\mathrm{abc}}\right.$ and $\left.\mathrm{I}_{\mathrm{abc}}\right)$ return to their initial values before the fault starting from $0.63 \mathrm{~s}$, by taking the reference values $\mathrm{U}_{\mathrm{abc}}=380 \mathrm{~V}$ and $\mathrm{f}=50 \mathrm{~Hz}$.

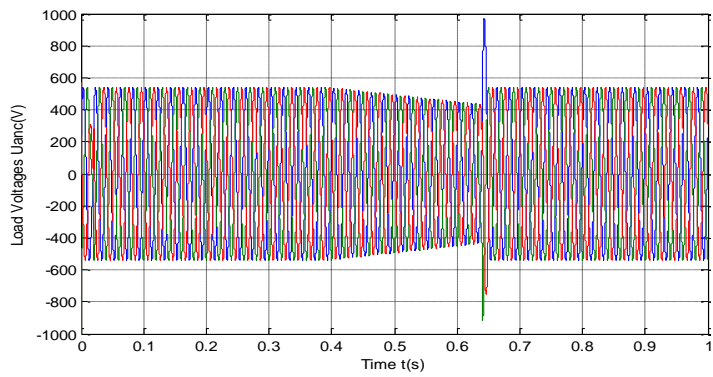

(a)

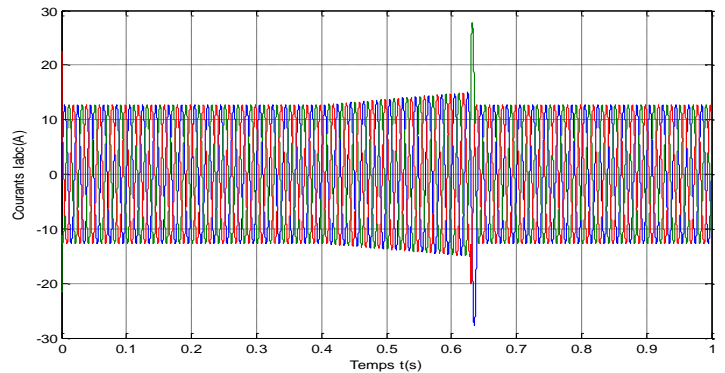

(b)

Fig. 13. Load (a. voltage and b. current) in under-load case. 
The network voltage starts decreasing at time $\mathrm{t}=0.4 \mathrm{~s}$ as shown in Fig 13(a). The minimum threshold value is reached at time $\mathrm{t}=0.53 \mathrm{~s}$. The current increases to its allowed maximum value as shown in Fig. 13(b), while the voltage decreased. When powered up, the entire system is triggered at around $0.63 \mathrm{~s}$; these quantities $\left(\mathrm{U}_{\mathrm{abc}}\right.$ and $\left.\mathrm{I}_{\mathrm{abc}}\right)$ return to their initial values before the defect, by taking the reference values $\mathrm{U}_{\mathrm{abc}}=380 \mathrm{~V}$ and $\mathrm{f}=50 \mathrm{~Hz}$.

\section{Conclusion}

The combination of wind and photovoltaic systems into a hybrid generation system (WSHGS), with their connection to the electrical grid can reduce the storage capacity of batteries and the total cost of the system. This work focuses on hybrid (PV/Wind) systems, the optimization of their energy yields and their connection to low voltage three-phase power grid through power converters with minimum power losses.

The approach adopted in this study consists on optimizing the different parts of the power conversion chain as well as the implementation of a protection system to stretch the generators life time and to ensure supplying consumers with electrical energy in case of grid failure.

The assessment of electric supply quality goes through the use of powerful tools that allow the checking of the three-phase electrical network supply parameters (voltage, frequency). For that, reason a wind system protection device is implemented i.e. The PLL, which is the essential element in reference voltages and frequencies estimation. This system is able to react to overvoltage, under voltages and frequency variations. Any decentralized production must be provided with such a device.

\section{References}

[1] Shezan SKA, Julai S, Kibria MA, Ullah KR, Saidur R, Chong WT, Akikur RK. Performance analysis of an off-grid wind-PV (photovoltaic)-diesel-battery hybrid energy system feasible for remote areas. Journal of Cleaner Production, 2016; 125: 121132.

[2] U. S. Energy Information Administration. 2014. [Online]. Available: http://www.eia.gov/countries/country-data.cfm?fips=AG

[3] Dahbi A, Hachemi M, Nait-Said N, Nait-Said MS. Realization and control of wind turbine connected to the grid by using PMSG. Energy Conversion and Management, 2014; 84: 346-353.

[4] Rahimi M. Modeling, control and stability analysis of grid connected PMSG based wind turbine assisted with diode rectifier and boos converter. Electrical Power and Energy Systems, 2017; 93: 84-96.

[5] Zhanfeng S, Changliang X, Tao L. Predictive Current Control of Three-Phase Grid-Connected Converters With Constant Switching Frequency for Wind Energy Systems. IEEE Transactions on Industrial Electronics, 2013; 60 (6): 2451-2464.

[6] Rasoul F, Amin R, Hamid RN, Roohollah F, Mohammad RC. FPGA-based real time incremental conductancemaximum power point tracking controller for photovoltaic systems. IET Power Electron, 2014; 7(5): 1294-1304.

[7] Brian P, Philip C, Sarath P. Advanced point of common coupling voltage controllers for grid-connected solar photovoltaic (PV) systems. Renewable Energy, 2016; 86: 1037-1044.

[8] Omid P, Kimmo K. Hierarchical control structure in micro grids with distributed generation: Island and grid-connected mode. Renewable and Sustainable Energy Reviews, 2015; 44:797-813.

[9] Ku Ahmad KNE, Abd Rahim N, Selvaraj J, Rivai A, Chaniago K. An effective islanding detection method for PV single-phase grid-connected inverter. Solar Energy, 2013; 97: 155-167.

[10] Darwish A, Abdel-khalik AS, Elserougi A, Ahmad S, Massoud A. Fault current contribution scenarios for grid-connected voltage source inverter-based distributed generation with an LCL filter. Electric Power System Research, 2013; 104: 93-103. 